\title{
Effect of implementation of a rapid response system on protocol adherence in a surgical ward
}

\author{
Friede Simmes ${ }^{1}$, Lisette Schoonhoven ${ }^{2,}{ }^{3}$, J oke Mintjes ${ }^{1}$, Bernard G. Fikkers ${ }^{4}$, J ohannes G. van der \\ Hoeven ${ }^{4}$ \\ 1. Faculty of Health and Social Studies, HAN University of Applied Sciences, Nijmegen, Netherlands. 2. Scientific Institute \\ for Quality of Healthcare, Radboud University Medical Centre, Nijmegen, Netherlands. 3. Faculty of Health Sciences, \\ University of Southampton, Southampton, UK. 4. Department of Intensive Care Medicine, Radboud University Medical \\ Centre, Nijmegen, Netherlands.
}

Correspondence: Friede Simmes, MScN, RN. Address: PO Box 6960, 6503 GL Nijmegen, Netherlands. E-mail: Friede.Simmes@HAN.nl

Received: October 7, 2013

Accepted: December 15, 2013

Online Published: December 19, 2013

DOI : 10.5430/jha.v3n3p23

URL: http://dx.doi.org/10.5430/jha.v3n3p23

\section{Abstract}

Objective: To describe the implementation of a rapid response system and adherence to its afferent limb in order to identify key elements for improvement.

Implementation: We developed a multifaceted implementation strategy to introduce the Rapid Response System (RRS) on a 60-bed surgical ward of a university hospital. The strategy included the use of clear objectives, key leaders, an early warning score (EWS) observation protocol and a two-tiered medical emergency team (MET) warning protocol, a 1-day training program including a before-after knowledge test, mandatory for nurses and optional for ward physicians, reminders and feedback.

Study design and methods: We retrospectively analyzed a sample of 10,653 patient days and 101 medical records of patients with a serious adverse event (SAE). Outcome measures were EWS recording rates, the nurse to ward physician and the ward physician to the MET calling rates following abnormal EWS recordings, and the indicators triggering these calls.

Results: EWS recordings were present in $90 \%$ of the day shifts, $88 \%$ of the evening shifts and $80 \%$ of the night shifts. EWSs were recorded at least once in 92/101 medical records in the three days before an SAE; in 91/101 records EWSs were abnormal at least once. In case of an abnormal score, the nurse called the ward physician once or more in $87 \%$ (79/91). After being called by the nurse, the ward physician called the MET once or more in $75 \%$ (59/79). However, in $18 \%$ (15/79) there was a delay of one or two days before the ward physician/MET was called. Overall, medical emergency team calls were absent or delayed in over $50 \%$.

Conclusions: After RRS implementation, recording of the EWS was high. Adequate warning in case of abnormal scores was suboptimal in nurses as well as ward physicians. Future implementation strategies should therefore be aimed at the interdisciplinary team.

\section{Key words}

Hospital rapid response team, Evaluation studies, Safety management, Surgery department 


\section{Introduction}

Most patients experience physiologic instability up to 48 hours prior to a serious adverse event (SAE) ${ }^{[1-4]}$. These warning signs are often not recognized or inadequately treated by the ward staff. Early recognition and treatment of abnormal vital signs is essential to prevent SAEs, such as cardiac arrest, death and unplanned intensive care unit (ICU) admissions. Based on these considerations the concept of the Rapid Response System (RRS) was developed ${ }^{[5]}$. An RRS consists of an afferent limb (detecting patients at risk and obtaining adequate help), an efferent limb (consisting of a dedicated rapid response team) and an administrative and data analysis limb. The RRS is highly recommended by the Institute for Healthcare Improvement ${ }^{[6]}$ and implemented in many countries ${ }^{[7]}$.

\subsection{Background}

Implementing an RRS is a complex process ${ }^{[8-12]}$. Even in matured RRSs, failure of the afferent limb is a persistent problem ${ }^{[13]}$ which may result in cardiac arrests ${ }^{[14]}$, hospital mortality ${ }^{[10,15,16]}$ or increased unplanned ICU admissions ${ }^{[10,17]}$. Until now, studies on the effects of an RRS remain equivocal ${ }^{[7,18-20]}$. Failure of implementation may partly explain these results ${ }^{[8]}$.

We implemented an RRS on the surgical ward and showed a statistically non-significant reduction in the number of cardiac arrests and/or unexpected deaths from $0.5 \%(7 / 1,376)$ before, to $0.25 \%(6 / 2,410)$ after implementation (odds ratio 0.43 ; 95\% confidence interval 0.14-1.3) ${ }^{[21]}$. In contrast, the number of unplanned ICU admissions increased from $2.47 \%$ $(34 / 1,376)$ before, to $4.15 \%(100 / 2,400)$ after implementation (odds ratio 1.66; 95\% confidence interval 1.07-2.55). We concluded that the decrease in cardiac arrests and/or unexpected deaths was not statistically significant partly due to the low baseline incidence.

The aim of this study was to describe the strategy used to implement the RRS and to measure the adherence of the ward staff to its afferent procedure in order to identify key elements for further improvement.

\subsection{I mplementation}

The RRS was implemented in a 60-bed surgical ward of a 960-bed university hospital in the Netherlands. Patients were admitted to the surgical ward for general surgery, including central or extensive peripheral vascular surgery, major oncologic surgery, lung surgery, extensive abdominal surgery, and trauma.

A multifaceted RRS implementation strategy was developed in 2006 and introduced between January and April 2007. The strategy included: setting clear objectives, appointing key leaders, introducing a tailored RRS procedure and a 1-day training program for nurses and ward physicians, and the use of follow-up reminders and feedback.

The objective of the RRS was to detect surgical patients at risk and treat them on the ward or assign them to a higher level of care in a timely manner. The implementation was supported by a group of key nurses and key physicians from the surgical ward and the ICU, and led by the project chair. The project chair was a research nurse from the intensive care. The key leaders developed an RRS adjusted to the hospital needs, based on the international consensus document on medical emergency teams (MET) ${ }^{[5]}$. They informed the nursing and medical staff about the theory and purpose of the RRS during staff meetings, supported by written information.

The protocol for early detection of patients at risk includes observation of the early warning score (EWS) and documentation of the EWS in the daily patient charts by the nurses, three times a day. A single-parameter EWS was chosen, including the following criteria for abnormal vital signs: respiratory rate $<8$ or $>30$ per minute, $\mathrm{O}_{2}$ saturation $<$ $90 \%$, systolic blood pressure $<90 \mathrm{mmHg}$ or $>200 \mathrm{mmHg}$, heart rate $<40$ or $>130$ per minute, a decrease of two points in the eye, motor, verbal (EMV) score, or if the nurse felt worried ${ }^{[22]}$. 
The protocol for obtaining adequate help was two-tiered. In the first tier, nurses had to call the ward physician immediately if one of the EWS warning criteria was met. Ward physicians were junior doctors, present in the hospital 24/7. The ward physician had to evaluate the patient at the bedside within 10 minutes. In the second tier the ward physicians activated the MET immediately if a serious situation existed or if the patient did not stabilize after an initial intervention. The ward physician was included to maintain continuity of care and limit the workload of the MET, in accordance with regular practice in the Netherlands ${ }^{[23]}$. The MET consisted of a critical care physician and a critical care nurse from the ICU. The MET was available 24/7. Finally, the SBAR (situation; background; assessment; and recommendation), a standardized way of communicating in critical situations ${ }^{[24]}$ was introduced in the protocol for both nurses and ward physicians.

A 1-day training program for nurses and ward physicians was developed, consisting of a theoretical part, a practical part focusing on the afferent procedure, and a discussion about ethical dilemmas related to the system. The practical part was a simulation-based training focusing on detection of the critically ill patient and communicating according to SBAR. The program was mandatory for nurses and optional for ward physicians. Approximately $90 \%$ of the nurses and $5 \%$ of the ward physicians attended the training. Nurses completed a knowledge test about the early warning score before- and after the training program. This knowledge test mainly included criteria for abnormal EWSs, and nurses could score a maximum of 100 points. Nurses completed the test during a team meeting within a period of two to four weeks before, and two to four weeks after the training program. In addition, nurses were asked to describe their perception of the RRS after having followed the training program. Nurses completed the EWS knowledge test before the training program in 64\% (60/94) and after the training program in 56\% (52/94). The score increased significantly from a median of 20 (IQR 10-30) to a median of 90 points (IQR 70-100, Mann-Whitney U 33, $p$.001). Nurses' perception on the RRS was positive. In particular, nurses were convinced that the availability of a MET would positively influence the quality of care for critically ill patients.

Reminders shaped in pocket-sized, laminated cards with the EWS criteria, the SBAR communication scheme, and the MET beeper number was given to the ward staff. Posters with the EWS criteria and the MET beeper numbers also were displayed in the wards. In addition, extra pulse oxymetry monitors were available on the ward and the EWS criteria were printed on the daily patient charts.

Feedback was given by newsletters showing EWS recording rates on the daily patient charts, nurse to ward physician- and ward physician to MET calling rates, and the time-interval between calls and arrival of the ward physician/MET. Newsletters were published every two months for nurses and every six months for ward physicians. Furthermore, progress of the RRS was discussed during regular staff meetings and at a special meeting once a year.

\section{Study design and methods}

We performed a retrospective analysis of daily patient charts. Furthermore, we analyzed medical records of patients who experienced an SAE. The need for informed consent was waived by the Medical Ethics Committee of district Arnhem-Nijmegen (MEC number: 2005/310).

To measure the effectiveness of our implementation strategy on afferent protocol adherence, we used the following outcome measures: EWS recording rates on the daily patient charts, EWS recording rates in the medical records of patients with an SAE, the nurse to ward physician- and the ward physician to MET calling rates following abnormal EWS recordings and the indicators triggering these calls.

A EWS was defined as complete if all EWS criteria were recorded. An SAE was defined as an unplanned ICU admission from the ward, a cardiac arrest or an unexpected death. The nurse to ward physician calling rate was defined as the number of ward physician calls from the nurse, divided by the number of days one or more abnormal EWSs were recorded. The 
ward physician to MET calling rate was defined as the number of MET calls from the ward physician divided by the number of days on which the ward physician was called by the nurse for an abnormal EWS.

We analyzed a sample of 10,653 patient days from 1,601 patients admitted at the ward between January 2008 to July 2009. Furthermore, we analyzed 101 medical records of patients who experienced an SAE between April 2007 and April 2009. Data were retrieved from the medical records starting two days before the day an SAE occurred, classified as day -2 , day -1 , and day 0 . We retrieved information about the nurse to the ward physician calls from the medical records and information about the ward physician to the MET calls from the electronic MET registration database.

\section{Results}

\subsection{EWS recording rates in the daily patient charts}

Figure 1 shows the percentage of vital signs recorded during the daytime, evening and night. Complete EWS recordings were present in $90 \%$ of the day shifts, $88 \%$ of the evening shifts and $80 \%$ of the night shifts.

Figure 1. Percentage of vital signs recorded in the daily patient charts

Note. $\mathrm{n}=10,653$ patient days. $\mathrm{O}_{2}$ sat $=\mathrm{O}_{2}$ saturation, resp.rate $=$ respiratory rate, syst.bp = systolic blood pressure, EMV = eye, motor, verbal score.

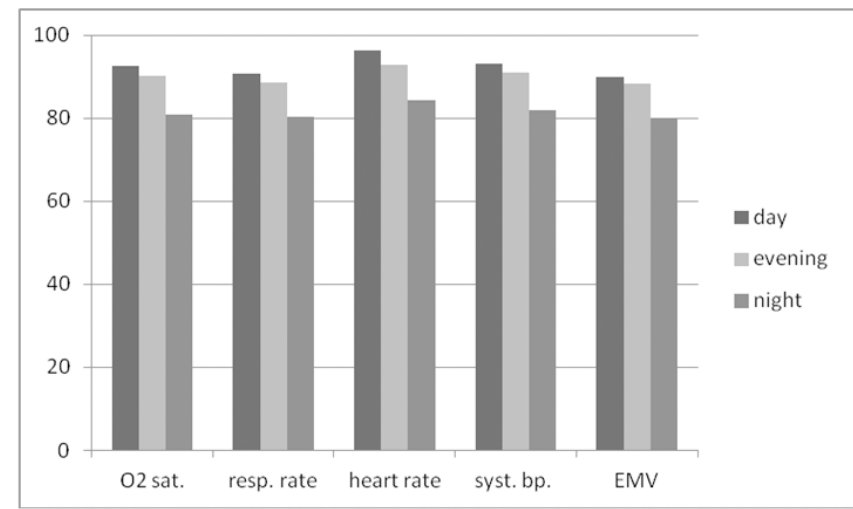

\subsection{EWS recording rates in the medical records of SAE patients and the calling rates following abnormal EWS recordings}

Table 1 shows the EWSs recording rates in the medical records before an SAE, stratified per day. EWS recordings increased from $58 \%$ (58/101) on day -2 , to $86 \%$ (87/101) on day 0 . Often no exact time indication was retrievable from the record.

Of the recorded EWSs, the percentage abnormal EWSs increased from $31 \%(18 / 58)$ on day -2 to $92 \%(80 / 87)$ on day 0 . In case of observed abnormal EWSs, nurses called the ward physician in $61 \%(11 / 18)$ on day -2 to $88 \%$ (70/80) on day 0. After being called by nurses, ward physicians called the MET in 27\% (3/11) on day -2 to $74 \%$ (52/70) on day 0.

Table 1. EWS recordings in the medical records and calling rates before an SAE stratified per day

\begin{tabular}{|c|c|c|c|c|c|c|}
\hline & \multicolumn{2}{|c|}{ Day-2 } & \multicolumn{2}{|c|}{ Day-1 } & \multicolumn{2}{|c|}{ Day 0} \\
\hline & $\mathbf{n}$ & (\%) & $\mathbf{n}$ & (\%) & $\mathbf{n}$ & (\%) \\
\hline EWS recorded in medical records (\% of SAEs) & 58 & (58) & 75 & (75) & 87 & (86) \\
\hline abnormal EWS (\% of recorded EWSs) & $18 / 58$ & (18) & $40 / 75$ & (53) & $80 / 87$ & $(92)$ \\
\hline ward physician calls from the nurses (\% of abnormal EWSs) & $11 / 18$ & $(61)$ & $32 / 40$ & (80) & $70 / 80$ & (88) \\
\hline $\begin{array}{l}\text { MET calls from the ward physician (\% of ward physician } \\
\text { calls in abnormal EWSs) }\end{array}$ & 3/11 & (27) & $11 / 32$ & (34) & $52 / 70$ & (74) \\
\hline
\end{tabular}

Note. $\mathrm{n}=101$ SAEs; EWS = early warning score; SAE = serious adverse event; day 2 = two days preceding the SAE, day 1 = one day preceding the SAE, day $0=$ the day of the SAE; MET = medical emergency team 
Figure 2 shows the EWS recordings in the medical records stratified per SAE. Recorded EWSs were abnormal at least once in 91\% (91/101) in the three days before the event. In 87\% (79/91) the nurse called the ward physician once or more. After being called by the nurse, the ward physician called the MET once or more in $75 \%$ (59/79). In 18\% (15/79) the nurse or the ward physician tried to stabilize the patient on the ward during one or two days before calling the ward physician/MET. Overall, in 48\% (44/91) of the SAEs with recorded abnormal EWSs, the MET was called on the same day the abnormal EWS was observed. Comparisons between the first and second year after RRS implementation showed no statistical differences in any of the outcomes (data not shown).

Figure 2. EWS recordings in the medical records and calling rates 3 days before an SAE, stratified per SAE

Note. SAEs = serious adverse events; EWS = early warning score.

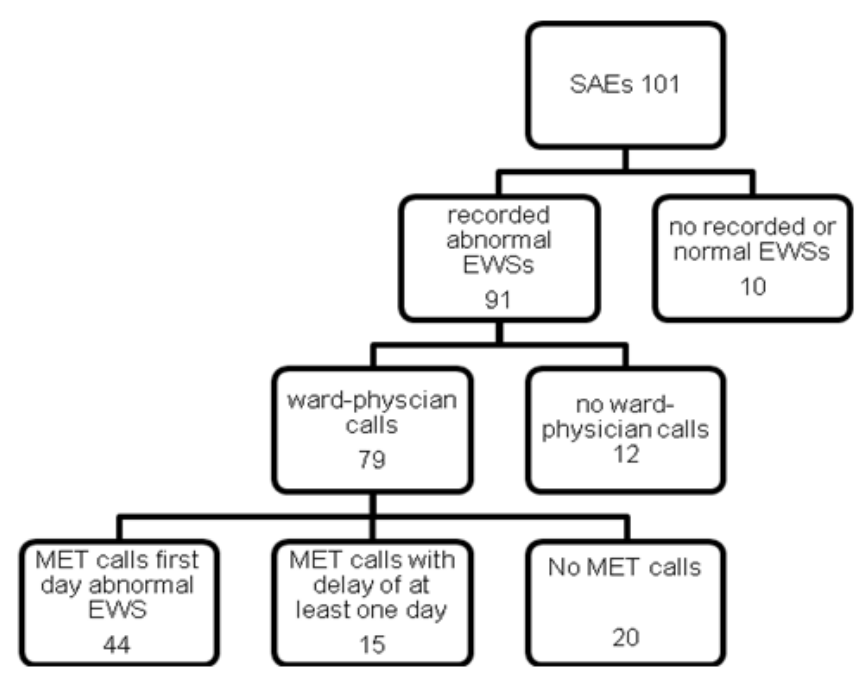

\subsection{I ndicators triggering calls}

Table 2 shows the nurse to ward physician and ward physician to MET triggering rate per vital sign. Abnormal EWSs were recorded in $46 \%(138 / 303)$ of the days before an SAE. In 72\% (100/138) information was given on the vital signs triggering the call for help and a total of 122 abnormal vital signs were registered. In 7\% (9/138) the nurse called the ward physician due to the worried criterion. In the remaining 21\% (29/138) no information was available on which EWS criterion triggered the call.

Nurses called the ward physician less often in cases of decreased systolic blood pressure (62\%) and decreased oxygen saturation (75\%). Ward physicians called the MET less often in cases of decreased systolic blood pressure (56\%), and increased heart rate (55\%). Recorded vital signs tended to be worse on day 0 compared with day -2 and day -1 , although the differences were not significant (data not shown).

Table 2. Indicators triggering ward physician and MET calls

\begin{tabular}{lllllll}
\hline Indicator & $\begin{array}{l}\text { abnormal } \\
\text { scores }\end{array}$ & $\begin{array}{l}\text { ward } \\
\text { physician calls }\end{array}$ & $\mathbf{( \% )}$ & MET calls & (\%) & $\begin{array}{l}\text { \% of abnormal } \\
\text { scores }\end{array}$ \\
\hline increased respiratory rate & 32 & 29 & 90 & $22 / 29$ & 76 & 69 \\
decreased oxygen saturation & 28 & 21 & 75 & $18 / 21$ & 86 & 64 \\
decreased systolic blood pres. & 40 & 25 & 62 & $14 / 25$ & 56 & 35 \\
decreased conscious state & 10 & 9 & 90 & $6 / 9$ & 67 & 60 \\
increased heart frequency & 12 & 11 & 92 & $6 / 11$ & 55 & 50 \\
\hline
\end{tabular}

Note. MET = medical emergency team 


\section{Discussion}

We described the implementation of an RRS on a surgical ward and the adherence to its afferent procedure in order to find key elements for improvement. Although the EWSs were observed in a large number, registration of those vital signs in medical records was often incomplete or missing. In 91\% of the medical records of SAE patients the EWS was abnormal at least once in the three days before the SAE occurred. In case of an abnormal EWS, the MET was called on the same day in only half of the SAE patients.

Our findings of delayed or absent MET calls in over 50\% are of concern, since studies showed an association between MET consult delays and SAEs ${ }^{[10,14-17,25]}$. Regular monitoring of vital signs is the first and foremost step of the afferent procedure for detecting critically ill patients. Our data show that nurses' knowledge of the EWS was adequate. Also complete EWS recordings in $80 \%-90 \%$ of the patient charts, depending on time of day, was acceptable. These results can probably be attributed to the multifaceted implementation strategy that we adopted. In the literature, initial simulation training ${ }^{[26-28]}$, knowledge of the warning criteria and reinforcement regarding the warning protocol have been identified as effective ways of introducing or improving the use of an RRS ${ }^{[26,29]}$. However, there was a lower observation frequency at night time compared with daytime. This fact has been shown by others ${ }^{[30]}$. To minimize sleep disturbances, nurses may be reluctant to observe EWSs during the night. Even though there is no international consensus concerning the frequency at which EWS observations should be made, a time interval of 12 hours may be too long ${ }^{[31]}$. Furthermore, less EWS values were copied from the daily patient charts in the medical records and often without an exact time indication. A patient's vital signs history should be easily accessible for clinicians ${ }^{[31]}$. This information is of importance in order to interpret actual vital scores.

Both nurses and ward physicians were less likely to call for help on days -2 and -1 compared with the day of the SAE itself. This may be partly explained by the fact that some patients were temporarily stabilized after a ward staff intervention. Possible other explanations for our findings are that ward staff underestimated the patient's risk of further deterioration. Most ward physicians are juniors and often lack the knowledge and experience to recognize medical emergency situations ${ }^{[32]}$. As only $5 \%$ of the ward physicians attended the one-day training program, this may certainly play a role. In contrast, ward staff may have felt that they were able to handle the situation by themselves ${ }^{[33,34]}$. For example, Pantazopolous (2012) found that nurses with a higher level of education or who attended a resuscitation course were less likely to call for help ${ }^{[35]}$. Furthermore, ward staff may have felt uncertain to call for help even when the patient met the warning criteria ${ }^{[34]}$. Nurses often rely on other nursing team members instead of procedures when making their decisions ${ }^{[36,37]}$. Nurses' and ward physicians' uncertainty increases when the attending ward physicians or MET do not

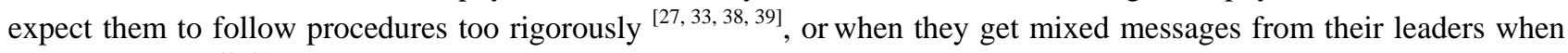
asking for help ${ }^{[40,41]}$.

To improve timely MET consultations, the next step could be to allow nurses to call the MET directly. However, this would undoubtedly result in an increased workload for the MET. For example, a study using almost the same warning criteria, found that $18 \%$ of all general ward patients showed abnormal scores at least once during admission ${ }^{[42]}$. This would result in MET calls in almost one out of five admitted patients. Moreover, research has shown that ward physicians

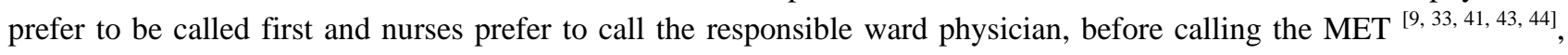
thereby involving ward physicians in the treatment of the patient at risk.

The low calling rate in case of a decreased systolic blood pressure of $<90 \mathrm{~mm}$ is remarkable. Even though changes in systolic blood pressure alone do not predict adverse events ${ }^{[45,46]}$, a decreased systolic blood pressure together with a decrease in urinary output, and/or respiratory changes and/or a decrease in consciousness is associated with a higher risk of death, as is a decreased systolic blood pressure with an abnormal blood gas analysis ${ }^{[46,47]}$. The low calling rate was also seen in case of decreased oxygen saturation and an increased heart rate. A decreased oxygen saturation of $90 \%$ or lower and an increased heart rate of $>120$ per minute are both associated with 5\%-10\% mortality, whereas a heart rate of $>150$ per minute is associated with $20 \%$ mortality ${ }^{[46]}$. A timely response on these abnormal vital signs is therefore of importance. 


\subsection{Key elements for improvement}

First, in order to increase accessibility for clinicians to patients' vital signs history, documentation of the observed vital signs into the medical records is needed.

Second, delays in calling for help when abnormal EWSs are observed should be minimized. Ward physicians play a crucial role and should encourage nurses to call them immediately when vital signs are abnormal, and they themselves should be encouraged to call the MET immediately if the patient's condition is critical or if the patient does not stabilize after initial treatment. To accomplish this, interdisciplinary team training on how to interact and manage unexpected critically ill patients may be helpful to improve collaboration. However, this training alone will probably not suffice since Fuhrmann (2009) showed that a one-day simulation based multi-professional training of staff did not affect staff awareness of patients at risk on the wards ${ }^{[42]}$. Consensus of shared perceptions regarding patient safety norms and behaviors by the ward staff is a premise for patient safety and successful quality improvement interventions ${ }^{[48]}$. This implicates that training programs concerning critically ill patients should be team oriented and integrated in a broader safety intervention program ${ }^{[49]}$. In addition, support by management facilitates activation of rapid response teams ${ }^{[43]}$. Thus, leadership is also an important component of implementation strategies for improving patient safety norms and behaviors.

Third, since the ward staff was less likely to call for help in case of a decreased systolic blood pressure, decreased oxygen saturation and an increased heart rate, the introduction of the aggregated, weighted parameter "track and trigger" system (AWTTS) ${ }^{[50]}$ may be considered as an aid to better interpret the deviations of one or more vital signs. The AWTTS allocates points to the vital parameters in a weighted manner. Since higher scores are associated with worse outcomes ${ }^{[51]}$, the use of an aggregated system may convince ward nurses and ward physicians to call for help if the score increases.

\subsection{Limitations of the study}

First, since this study took place in one surgical ward of a Dutch university hospital, the relevance for other settings is unclear, although afferent limb failure is a frequently reported problem. Second, although we included many patient days at risk, our sample included only 101 SAEs. Third, due to the retrospective character, we probably missed some observed, but not recorded abnormal EWS occurrences. In addition, since exact time indications were often missing along with recorded abnormal EWSs, timelines were defined in days on which ward physicians and MET were called following an abnormal EWS observation.

\section{Conclusions}

Use of a tailored multifaceted strategy for implementation of the RRS, resulted in sufficient monitoring of vital signs by ward nurses. However, the afferent limb showed deficiencies in documentation of vital signs in the medical records and calls for help by the nurse and the ward-physician in case of observed abnormal EWSs. Our initial implementation strategy was primarily aimed at the nurses, future implementation strategies should be aimed at the interdisciplinary ward team.

\section{Acknowledgements}

The authors would thank students and Ans Rensen, lecturer of the bachelor of nursing degree from the HAN University for their contributions in gathering data. They also would thank Monique Born who tested the nurses' EWS knowledge.

\section{Contributors}

All contributors planned the study, FS, AR and MB participated in data acquisition. FS conducted the analyses and drafted the manuscript with input of all contributors. 


\section{Funding}

This research received no specific grant from any funding agency in the public, commercial or not-for-profit sectors.

\section{References}

[1] Hillman KM, Bristow PJ, Chey T, Daffurn K, Jacques T, Norman SL, et al. Antecedents to hospital deaths. Intern Med J. 2001 Aug; 31(6): 343-348. PMid: 11529588. http://dx.doi.org/10.1046/j.1445-5994.2001.00077.x

[2] Hillman KM, Bristow PJ, Chey T, Daffurn K, Jacques T, Norman SL, et al. Duration of life-threatening antecedents prior to intensive care admission. Intensive Care Med. 2002 Nov; 28(11): 1629-1634. PMid: 12415452. http://dx.doi.org/10.1007/s00134-002-1496-y

[3] Goldhill DR, White SA, Sumner A. Physiological values and procedures in the $24 \mathrm{~h}$ before ICU admission from the ward. Anaesthesia. 1999 Jun; 54(6): 529-534. PMid: 10403864. http://dx.doi.org/10.1046/j.1365-2044.1999.00837.x

[4] Kause J, Smith G, Prytherch D, Parr M, Flabouris A, Hillman K, et al. A comparison of antecedents to cardiac arrests, deaths and emergency intensive care admissions in Australia and New Zealand, and the United Kingdom--the ACADEMIA study. Resuscitation. 2004 Sep; 62(3): 275-282. PMid: 15325446. http://dx.doi.org/10.1016/j.resuscitation.2004.05.016

[5] DeVita MA, Bellomo R, Hillman K, Kellum J, Rotondi A, Teres D, et al. Findings of the first consensus conference on medical emergency teams. Crit Care Med. 2006 Sep; 34(9): 2463-2478. PMid: 16878033. http://dx.doi.org/10.1097/01.CCM.0000235743.38172.6E

[6] Berwick DM, Calkins DR, McCannon CJ, Hackbarth AD. The 100,000 lives campaign: setting a goal and a deadline for improving health care quality. JAMA. 2006 Jan 18; 295(3): 324-327. PMid: 16418469. http://dx.doi.org/10.1001/jama.295.3.324

[7] Chan PS, Jain R, Nallmothu BK, Berg RA, Sasson C. Rapid Response Teams: A Systematic Review and Meta-analysis. Arch Intern Med. 2010 Jan 11; 170(1): 18-26. PMid: 20065195. http://dx.doi.org/10.1001/archinternmed.2009.424

[8] Hillman K, Chen J, Cretikos M, Bellomo R, Brown D, Doig G, et al. Introduction of the medical emergency team (MET) system: a cluster-randomised controlled trial. Lancet. 2005 Jun 18; 365(9477): 2091-2097.

http://dx.doi.org/10.1016/S0140-6736(05)66733-5

[9] Jones D, Bates S, Warrillow S, Goldsmith D, Kattula A, Way M, et al. Effect of an education programme on the utilization of a medical emergency team in a teaching hospital. Intern Med J. 2006 Apr; 36(4): 231-236. PMid: 16640740. http://dx.doi.org/10.1111/j.1445-5994.2006.01045.x

[10] Calzavacca P, Licari E, Tee A, Egi M, Downey A, Quach J, et al. The impact of Rapid Response System on delayed emergency team activation patient characteristics and outcomes-A follow-up study. Resuscitation. 2009 Oct 23; 81(1): 31-35. PMid: 19854557. http://dx.doi.org/10.1016/j.resuscitation.2009.09.026

[11] Tee A, Calzavacca P, Licari E, Goldsmith D, Bellomo R. Bench-to-bedside review: The MET syndrome--the challenges of researching and adopting medical emergency teams. Crit Care. 2008; 12(1): 205-211. PMid: 18254927. http://dx.doi.org/10.1186/cc6199

[12] Santamaria J, Tobin A, Holmes J. Changing cardiac arrest and hospital mortality rates through a medical emergency team takes time and constant review. Crit Care Med. 2010 Feb; 38(2): 445-450. PMid: 20029341. http://dx.doi.org/10.1097/CCM.0b013e3181cb0ff1

[13] Sandroni C, Cavallaro F. Failure of the afferent limb: a persistent problem in rapid response systems. Resuscitation. 2011 Jul; 82(7): 797-798. PMid: 21641498. http://dx.doi.org/10.1016/j.resuscitation.2011.04.012

[14] Quach JL, Downey AW, Haase M, Haase-Fielitz A, Jones D, Bellomo R. Characteristics and outcomes of patients receiving a medical emergency team review for respiratory distress or hypotension. J Crit Care. 2008 Sep; 23(3): 325-331. PMid: 18725036. http://dx.doi.org/10.1016/j.jcrc.2007.11.002

[15] Galhotra S, DeVita MA, Simmons RL, Dew MA. Mature rapid response system and potentially avoidable cardiopulmonary arrests in hospital. Qual Saf Health Care. 2007 Aug; 16(4): 260-265. PMid: 17693672. http://dx.doi.org/10.1136/qshc.2007.022210

[16] Calzavacca P, Licari E, Tee A, Egi M, Haase M, Haase-Fielitz A, et al. A prospective study of factors influencing the outcome of patients after a Medical Emergency Team review. Intensive Care Med. 2008 Nov; 34(11): 2112-2116. PMid: 18651130. http://dx.doi.org/10.1007/s00134-008-1229-y

[17] Trinkle RM, Flabouris A. Documenting Rapid Response System afferent limb failure and associated patient outcomes. Resuscitation. 2011 Mar 29; 82(7): 810-814. PMid: 21497982. http://dx.doi.org/10.1016/j.resuscitation.2011.03.019

[18] Ranji SR, Auerbach AD, Hurd CJ, O'Rourke K, Shojania KG. Effects of rapid response systems on clinical outcomes: systematic review and meta-analysis. J Hosp Med. 2007 Nov; 2(6): 422-432. PMid: 18081187. http://dx.doi.org/10.1002/jhm.238 
[19] Winters BD, Pham JC, Hunt EA, Guallar E, Berenholtz S, Pronovost PJ. Rapid response systems: a systematic review. Crit Care Med. 2007 May; 35(5): 1238-1243. PMid: 17414079. http://dx.doi.org/10.1097/01.CCM.0000262388.85669.68

[20] Massey D, Aitken LM, Chaboyer W. Literature review: do rapid response systems reduce the incidence of major adverse events in the deteriorating ward patient? J Clin Nurs. 2010 Dec; 19(23-24): 3260-3273. PMid: 21029228.

http://dx.doi.org/10.1111/j.1365-2702.2010.03394.x

[21] Simmes F, Schoonhoven L, Mintjes J, Fikkers BG, Van der Hoeven JG. Effects of a rapid response system on quality of life: a prospective cohort study in surgical patients before and after implementing a rapid response system. Health Qual Life Outcomes. 2013 May 1; 11: 74-7525-11-74.

[22] Bellomo R, Goldsmith D, Uchino S, Buckmaster J, Hart G, Opdam H, et al. Prospective controlled trial of effect of medical emergency team on postoperative morbidity and mortality rates. Crit Care Med. 2004 Apr; 32(4): 916-921. PMid: 15071378. http://dx.doi.org/10.1097/01.CCM.0000119428.02968.9E

[23] Ludikhuize J, Hamming A, De Jonge E, Fikkers BG. Rapid response systems in The Netherlands. Jt Comm J Qual Patient Saf. 2011 Mar; 37(3): 138-44, 97.

[24] Haig KM, Sutton S, Whittington J. SBAR: a shared mental model for improving communication between clinicians. Jt Comm J Qual Patient Saf. 2006 Mar; 32(3): 167-175. PMid: 16617948.

[25] Tirkkonen J, Yla-Mattila J, Olkkola KT, Huhtala H, Tenhunen J, Hoppu S. Factors associated with delayed activation of medical emergency team and excess mortality: an Utstein-style analysis. Resuscitation. 2013 Feb; 84(2): 173-178. PMid: 23009981. http://dx.doi.org/10.1016/j.resuscitation.2012.09.021

[26] Donaldson N, Shapiro S, Scott M, Foley M, Spetz J. Leading successful rapid response teams: A multisite implementation evaluation. J Nurs Adm. 2009 Apr; 39(4): 176-181. PMid: 19359889. http://dx.doi.org/10.1097/NNA.0b013e31819c9ce9

[27] Jones L, King L, Wilson C. A literature review: factors that impact on nurses' effective use of the Medical Emergency Team (MET). J Clin Nurs. 2009 Dec; 18(24): 3379-3390. PMid: 20487489. http://dx.doi.org/10.1111/j.1365-2702.2009.02944.x

[28] Wehbe-Janek H, Lenzmeier CR, Ogden PE, Lambden MP, Sanford P, Herrick J, et al. Nurses' perceptions of simulation-based interprofessional training program for rapid response and code blue events. J Nurs Care Qual. 2012 Jan-Mar; 27(1): 43-50. PMid: 21849908. http://dx.doi.org/10.1097/NCQ.0b013e3182303c95

[29] Foraida MI, DeVita MA, Braithwaite RS, Stuart SA, Brooks MM, Simmons RL. Improving the utilization of medical crisis teams (Condition C) at an urban tertiary care hospital. J Crit Care. 2003 Jun; 18(2): 87-94. PMid: 12800118. http://dx.doi.org/10.1053/jcrc.2003.50002

[30] Hands C, Reid E, Meredith P, Smith GB, Prytherch DR, Schmidt PE, et al. Patterns in the recording of vital signs and early warning scores: compliance with a clinical escalation protocol. BMJ Qual Saf. 2013 Apr 19.

[31] DeVita MA, Smith GB, Adam SK, Adams-Pizarro I, Buist M, Bellomo R, et al. "Identifying the hospitalised patient in crisis" - a consensus conference on the afferent limb of rapid response systems. Resuscitation. 2010 Apr; 81(4): 375-382. PMid: 20149516. http://dx.doi.org/10.1016/j.resuscitation.2009.12.008

[32] Kellett J. Prognostication - the lost skill of medicine. Eur J Intern Med. 2008 May; 19(3): 155-164. PMid: 18395158. http://dx.doi.org/10.1016/j.ejim.2007.09.002

[33] Azzopardi P, Kinney S, Moulden A, Tibballs J. Attitudes and barriers to a Medical Emergency Team system at a tertiary paediatric hospital. Resuscitation. 2011 Feb; 82(2): 167-174. PMid: 21106289. http://dx.doi.org/10.1016/j.resuscitation.2010.10.013

[34] Jones D, Bellomo R, Bates S, Warrillow S, Goldsmith D, Hart G, et al. Patient monitoring and the timing of cardiac arrests and medical emergency team calls in a teaching hospital. Intensive Care Med. 2006 Sep; 32(9): 1352-1356. PMid: 16826391. http://dx.doi.org/10.1007/s00134-006-0263-x

[35] Pantazopoulos I, Tsoni A, Kouskouni E, Papadimitriou L, Johnson EO, Xanthos T. Factors influencing nurses' decisions to activate medical emergency teams. J Clin Nurs. 2012 Sep; 21(17-18): 2668-2678. PMid: 22889450. http://dx.doi.org/10.1111/j.1365-2702.2012.04080.x

[36] Wynn JD, Engelke MK, Swanson M. The front line of patient safety: staff nurses and rapid response team calls. Qual Manag Health Care. 2009 Jan-Mar; 18(1): 40-47. PMid: 19148028. http://dx.doi.org/10.1097/01.QMH.0000344592.63757.51

[37] Cioffi J. Recognition of patients who require emergency assistance: a descriptive study. Heart Lung. 2000 Jul; 29 (4): $262-268$. PMid: 10900063. http://dx.doi.org/10.1067/mhl.2000.108327

[38] Cioffi J. Nurses' experiences of making decisions to call emergency assistance to their patients. J Adv Nurs. 2000 Jul; 32(1): 108-114. PMid: 10886441. http://dx.doi.org/10.1046/j.1365-2648.2000.01414.x

[39] Odell M, Victor C, Oliver D. Nurses' role in detecting deterioration in ward patients: systematic literature review. J Adv Nurs. 2009 Oct; 65(10): 1992-2006. PMid: 20568317. http://dx.doi.org/10.1111/j.1365-2648.2009.05109.x

[40] Shapiro SE, Donaldson NE, Scott MB. Rapid response teams seen through the eyes of the nurse. Am J Nurs. 2010 Jun; $110(6)$ : 28-34. PMid: 20505459. http://dx.doi.org/10.1097/01.NAJ.0000377686.64479.84 
[41] Bagshaw SM, Mondor EE, Scouten C, Montgomery C, Slater-MacLean L, Jones DA, et al. A survey of nurses' beliefs about the medical emergency team system in a canadian tertiary hospital. Am J Crit Care. 2010 Jan; 19(1): 74-83. PMid: 19542059. http://dx.doi.org/10.4037/ajcc2009532

[42] Fuhrmann L, Perner A, Klausen TW, Ostergaard D, Lippert A. The effect of multi-professional education on the recognition and outcome of patients at risk on general wards. Resuscitation. 2009 Dec; 80(12): 1357-1360. PMid: 19765884. http://dx.doi.org/10.1016/j.resuscitation.2009.07.002

[43] Astroth KS, Woith WM, Stapleton SJ, Degitz RJ, Jenkins SH. Qualitative exploration of nurses' decisions to activate rapid response teams. J Clin Nurs. 2013 Feb 7. PMid: 23388057.

[44] McFarlan SJ, Hensley S. Implementation and outcomes of a rapid response team. J Nurs Care Qual. 2007 Oct-Dec; 22(4): 307-13, quiz 14-5. PMid: 17873726. http://dx.doi.org/10.1097/01.NCQ.0000290410.19769.41

[45] Conen D, Leimenstoll BM, Perruchoud AP, Martina B. Routine blood pressure measurements do not predict adverse events in hospitalized patients. Am J Med. 2006 Jan; 119(1): 70.e17-70.e22.

[46] Bleyer AJ, Vidya S, Russell GB, Jones CM, Sujata L, Daeihagh P, et al. Longitudinal analysis of one million vital signs in patients in an academic medical center. Resuscitation. 2011 Nov; 82(11): 1387-1392. PMid: 21756971. http://dx.doi.org/10.1016/j.resuscitation.2011.06.033

[47] Jacques T, Harrison GA, McLaws ML, Kilborn G. Signs of critical conditions and emergency responses (SOCCER): a model for predicting adverse events in the inpatient setting. Resuscitation. 2006 May; 69(2): 175-183. PMid: 16497427. http://dx.doi.org/10.1016/j.resuscitation.2005.08.015

[48] Sexton JB, Berenholtz SM, Goeschel CA, Watson SR, Holzmueller CG, Thompson DA, et al. Assessing and improving safety climate in a large cohort of intensive care units. Crit Care Med. 2011 May; 39(5): 934-939. PMid: 21297460. http://dx.doi.org/10.1097/CCM.0b013e318206d26c

[49] Bion JF, Abrusci T, Hibbert P. Human factors in the management of the critically ill patient. Br J Anaesth. 2010 Jul; 105(1): 26-33. PMid: 20511333. http://dx.doi.org/10.1093/bja/aeq126

[50] Subbe CP, Kruger M, Rutherford P, Gemmel L. Validation of a modified Early Warning Score in medical admissions. QJM 2001 Oct; 94(10): 521-526. PMid: 11588210. http://dx.doi.org/10.1093/qjmed/94.10.521

[51] Paterson R, MacLeod DC, Thetford D, Beattie A, Graham C, Lam S, et al. Prediction of in-hospital mortality and length of stay using an early warning scoring system: clinical audit. Clin Med. 2006 May; 6(3): 281-284. PMid: 16826863.

http://dx.doi.org/10.7861/clinmedicine.6-3-281 